\title{
Ethnic Equity Implications in the Management of Pseudofolliculitis Barbae
}

\author{
Divya Sharma, BS, Yoseph Dalia, MD, MBA, and Tejesh S. Patel, MD
}

One major issue facing the health care system in the United States is the disparity in health care management of diseases that affect minority patient populations. Pseudofolliculitis barbae (PFB) is very common in Black men. It presents as skin-colored to erythematous, follicular or perifollicular papules and pustules predominantly on the neck and chin. The most definitive treatment for PFB is cessation of close shaving. However, many Black men are forced to comply with "clean-shaven" policies in the workforce. For those who are able to obtain medical waivers, there is significant time and costs associated with this, especially if they must wait to receive this waiver from a dermatologist. If primary care providers are able to identify the disease and spread awareness of its legitimacy, it may be easier for patients to receive the necessary waivers and may encourage employers to reflect on the ethnic equity of this practice. Our professional support can help reduce stigma and lead to improvements in the physical and psychological health of this historically mistreated population. (J Am Board Fam Med 2022;35:173-174.)

Keywords: Access to Health Care, African Americans, Hair Diseases, Health Equity, Humanities, Primary Health Care, Pseudofolliculitis Barbae, Workforce

\section{Introduction}

Health care inequalities are a systemic issue that requires systemic changes; however, there are individual practice changes that can be made that will greatly reduce the burden on our patients. One of the major issues facing the health care system in the United States is the prominent disparity in health care management of diseases that affect minority patient populations. One example of this is in the management of pseudofolliculitis barbae (PFB), also known as "shaving bumps," sycosis barbae, and traumatic folliculitis of the beard. PFB most often presents as skin-colored to erythematous, follicular or perifollicular papules and pustules in the neck, chin, and less often the cheeks (Figure 1). PFB is very common in Black men, with an estimated

This article was externally peer reviewed.

Submitted 18 April 2021; revised 10 June 2021; accepted 15 June 2021.

From Division of Dermatology, Northeast Ohio Medical University, Rootstown, OH (DS); Kaplan-Amonette Department of Dermatology, University of Tennessee Health Science Center, Memphis (YD, TSP).

Funding: none reported.

Conflict of interest: none reported.

Corresponding author: Yoseph Dalia, MD, MBA, KaplanAmonette Department of Dermatology, University of Tennessee Health Science Center, 930 Madison Avenue, Suite 840 Memphis, TN 38163 (E-mail: ydalia@uthsc.edu). prevalence between $45 \%$ to $83 \%$ in men of subequatorial African ancestry. ${ }^{1}$ It is believed to be caused by a foreign-body inflammatory reaction due to strongly curved hairs emerging parallel to and subsequently re-entering the skin, usually after shaving. ${ }^{1}$ Over time, this can lead to permanent scarring. ${ }^{2}$ The most definitive treatment for PFB is the cessation of shaving. ${ }^{2}$

\section{Challenges: Past and Present}

Little research was done about this disease until the 1960s and 1970s, a time when more and more Black men were enrolling in the military and were subsequently subject to its "clean shave policy." This policy was initially enforced to ensure good personal hygiene and a secure gas mask seal and to instill discipline., Thus, interpersonal friction and stigma arose if Black men were not able to shave due to PFB and consequently had an appearance violating the previously mentioned policy. There was a recent publication in Military Medicine addressing the discrimination Black men in the military face with regards to shaving, with additional studies showing Black men in the US Army were more likely to underreport the severity of PFB or refuse medical help for fear of harassment. ${ }^{3,5}$ Outside the military, Black men who are not clean- 
Figure 1. Multiple perifollicular papules and pustules in the beard area.

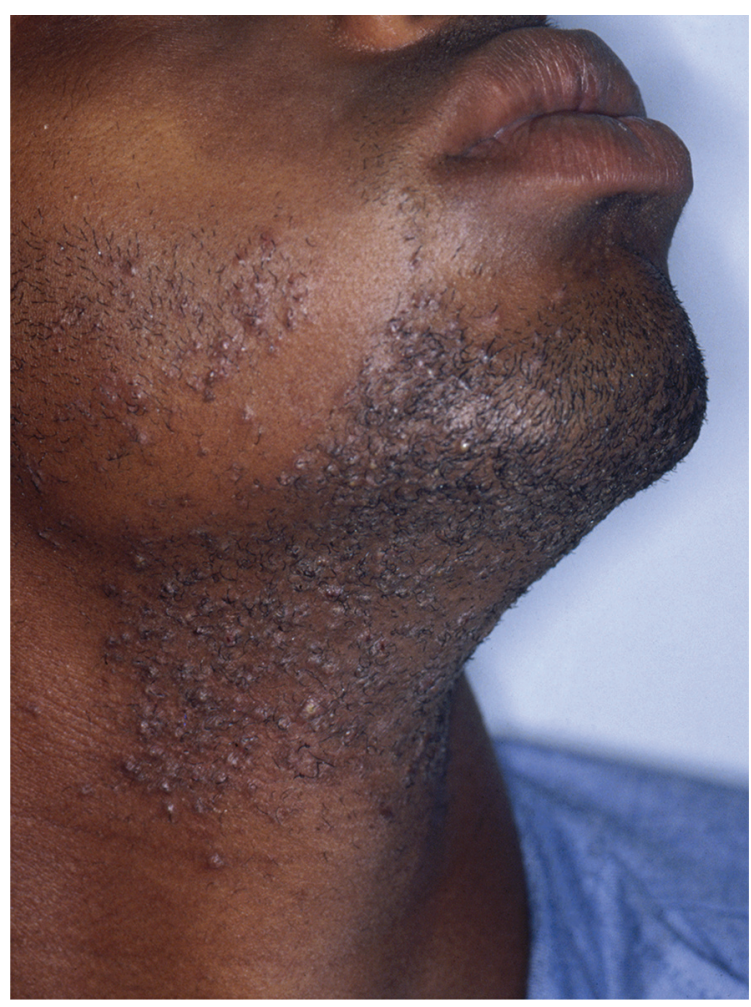

shaven are often deemed as unprofessional and subjected to discrimination. ${ }^{6,7}$ Ethnocentric societal pressures, stigma, and racial biases have persisted in our society. For example, a police officer had to have a medical waiver from the cleanly shaven policy renewed every 60 days. ${ }^{7}$ The time and costs associated with obtaining this waiver place an unfair burden on those afflicted with this condition.

\section{Action Statement}

This societal mistreatment of patients with PFB not only represents a failure of our country to treat these men with dignity but also an opportunity for our profession to advocate for these patients. Increased awareness of this condition and its management by primary care providers may help reduce the impact of this disease on our patients. Therefore, it is imperative the primary care provider can diagnose and provide patient-centric care, which includes the documentation and support needed to stop workplace discrimination. In light of various professional organizations, including the Centers for Disease Control and Prevention, recognizing racial injustice as a serious public health issue, all physicians can work toward educating the general population, including employers, about the legitimacy of PFB.

We must also continue to pursue research in this condition to provide affordable and practical management options for patients who strongly desire keeping a beard. Our professional support actions can help reduce stigma and lead to improvements in the physical and psychological well-being of this historically mistreated population.

Image used with permission from VisualDx (www.visualdx.com).

To see this article online, please go to: http://jabfm.org/content/ 35/1/173.full.

\section{References}

1. Gray J, McMichael AJ. Pseudofolliculitis barbae: understanding the condition and the role of facial grooming. Int J Cosmet Sci 2016;38 Suppl 1:24-7.

2. Kelly A, Serrano A. Pseudofolliculitis barbae. In: Kelly A, Taylor SC, Lim HW, Serrano A, eds. Taylor and Kelly's dermatology for skin of color. 2nd ed. New York: McGraw-Hill; 2016. p. 264-9.

3. Okonkwo E, Neal B, Harper HL. Pseudofolliculitis barbae in the military and the need for social awareness. Mil Med 2021;Feb 9:usab036.

4. Tshudy MT, Cho S. Pseudofolliculitis barbae in the U.S. military, a review. Military Medicine 2021;186: e52-e57.

5. Brauner GJ, Flandermeyer KL. Pseudofolliculitis barbae: medical consequences of interracial friction in the US Army. Cutis 1979;23:61-6.

6. Antrum v. Washington Metro [Internet]. Area Transit Auth., 710 F. Supp. 2d 112 (D.D.C. 2010); 2010. Available from: https://www.govinfo.gov/content/pkg/ USCOURTS-dcd-1_08-cv-00203/pdf/USCOURTSdcd-1_08-cv-00203-0.pdf.

7. Lewis v. Univ. of Pa. [Internet]. Civil Action No. 165874 (E.D. Pa. Jan. 29, 2018); 2018. Available from: https://www.govinfo.gov/content/pkg/USCOURTSpaed-2_16-cv-05874/pdf/USCOURTS-paed-2_16cv-05874-0.pdf. 